\title{
Молибден в донных отложениях озера Большой Вудъявр, Мурманская область: вертикальное распределение и формы нахождения
}

\author{
Слуковский 3.И. ${ }^{1}$, Мицуков А.С. ${ }^{2}$, Даувальтер В.А. ${ }^{2}$ \\ ${ }^{1}$ Институт геологии КарНЦ РАН, Петрозаводск, slukovsky87@gmail.com \\ ${ }^{2}$ Институт проблем промышленной экологии Севера КНЦ РАH, Anamumbl,mitsukovaleks@gmail.com, \\ vladimir@dauvalter.com
}

Аннотация. В статье приводятся результаты исследования геохимической специфики современных донных отложений оз. Большой Вудъявр, испытывающей антропогенную нагрузку в результате деятельности АО «Апатит». Анализируется поведение основного загрязнителя водоема - молибдена, поступающего в озеро с рудными водами. Приводятся сведения о формах нахождения этого металла в донных отложениях оз. Большой Вудъявр.

Ключевые слова: молибден, донные отложения, озеро Большой Вудъявр, оценка загрязнения.

\section{Molybdenum in bottom sediments of Lake Bolshoi Vudjavr, Murmansk region: vertical distribution and forms of this metal}

\author{
Slukovskii Z.I. ${ }^{1}$, Mitsukov A.S. ${ }^{2}$, Dauvalter V.A. ${ }^{2}$ \\ ${ }^{1}$ Institute of Geology Karelian Research Centre of RAS, Petrozavodsk, slukovsky87@gmail.com \\ ${ }^{2}$ Institute of the North Industrial Ecology Problems, Kola Science Centre of RAS, Apatity, \\ mitsukovaleks@gmail.com
}

\begin{abstract}
The article reviews results of an investigation of the geochemical specific features of modern sediments of Lake Bolshoi Vudjavr, which is under anthropogenic load in result of the activity of JSC «Apatit». The behavior of main pollutant of reservoir - molybdenum, entering the lake coupled with ore waters has been studied. As the title implies, the article describes forms of molybdenum in the sediments of Lake Bolshoi Vudjavr.
\end{abstract}

Key words: molybdenum, bottom sediment, Lake Bolshoi Vudjavr, assessment of pollution.

\section{Введение}

В условиях антропогенного воздействия горнорудной промышленности Мурманской области на состояние окружающей среды водные экосистемы испытывают наиболее заметные техногенные нагрузки. В условиях Крайнего Севера, из-за низкой способности водоемов к самоочищению, техногенное влияние приводит к необратимым последствиям для природной среды, что выражается в трансформации химического состава воды, донных отложений (ДО) водных объектов и в смене комплексов и групп живых организмов. Самые сложные ситуации, близкие к условиям экологического риска или кризиса, наблюдаются в водных объектах, расположенных в непосредственной близости от техногенного источника преобразования окружающей среды. Одним из таких объектов является оз. Большой Вудъявр (далее Б. Вудъявр), на берегу которого расположен г. Кировск Мурманской области (рис. 1).

Оз. Б. Вудъявр - самый крупный внутренний водоем Хибинского горного массива. В северовосточную часть оз. Б. Вудъявр поступают шахтные воды рудников «Расвумчоррский» и «Кировский» (ОАО «Апатит»). Кроме того, озеро, несомненно, испытывает антропогенную нагрузку вследствие близости к нему городской среды и автомобильных и железнодорожных путей сообщения, связывающих г. Кировск и территории рудников. Ранее проводившиеся исследования ДО оз. Б. Вудъявр (Югай и др., 2013) выявили высокий уровень загрязнения водоема различными элементами, в том числе тяжелыми металлами $(\mathrm{Cu}, \mathrm{Zn}, \mathrm{Ni}, \mathrm{Sr}$ и др.). При этом химическое загрязнение озера сказалось на развитии живых организмов водоема, в частности была отмечена трансформация состава диатомового комплекса оз. Б. Вудъявр в период интенсивной антропогенной нагрузки на водный объект (Денисов и др., 2006). 


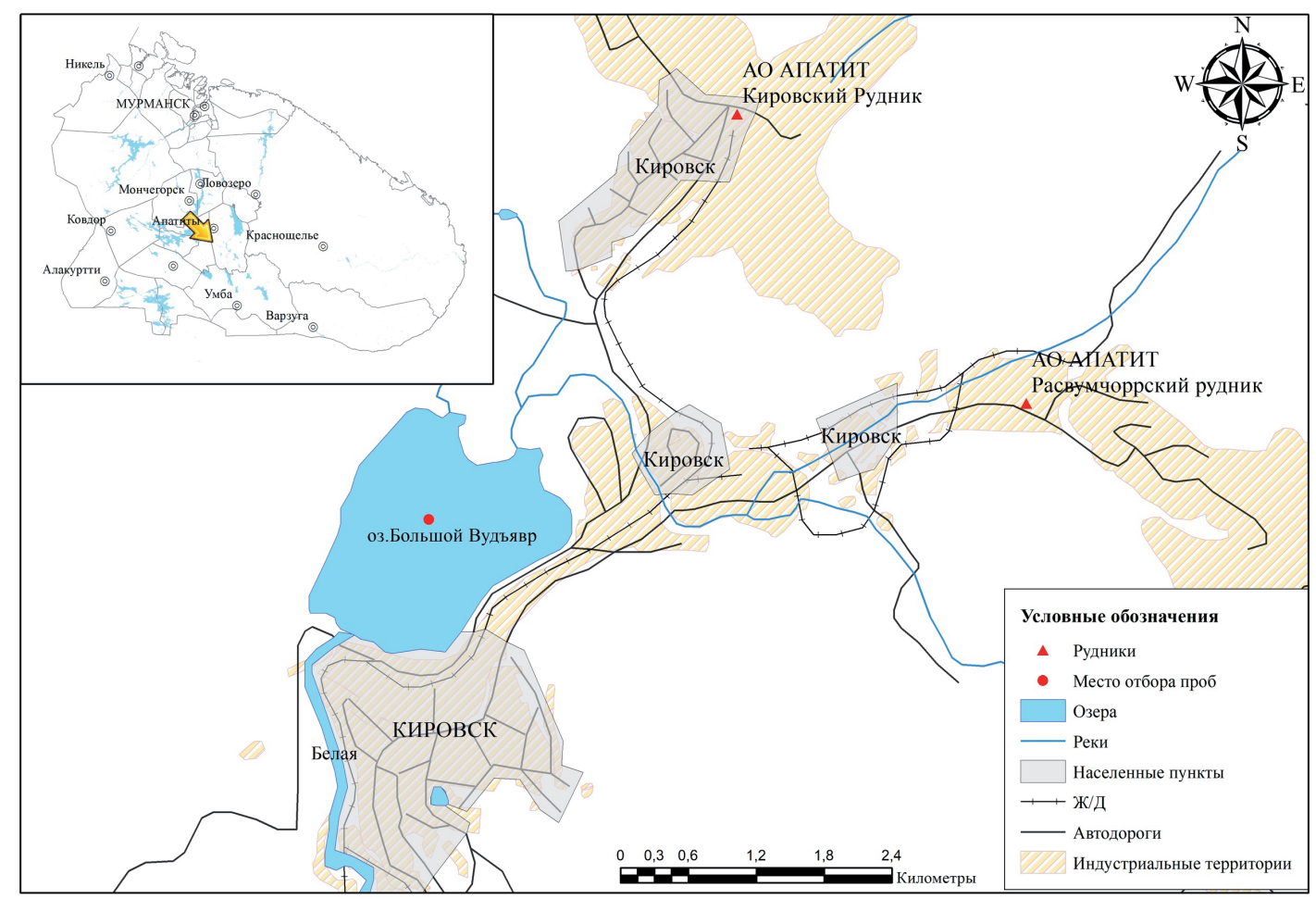

Рис. 1. Карта-схема района исследования. Fig. 1. Map of the research area.

Известно, что в природных водах, приуроченных к району разработки месторождения апатитнефелиновых руд в районе Хибинского горного массива, обнаружено присутствие молибдена (Мо) в количествах, значительно превышающих ПДК для рыбохозяйственных водоемов (Молибден..., 2016). Большая часть этих вод поступает в оз. Б. Вудъявр, где концентрации Мо в 25 раз превышают нормативные показатели (Чукаева, Матвеева, 2018). Следует отметить, что Мо сравнительно недавно вошел в число контролируемых показателей в нашей стране, а при высокой стоимости экологических платежей за его сброс возросла заинтересованность предприятий в очистке сточных вод от этого металла. Актуальной проблемой является анализ поведения Мо в современных ДО оз. Б. Вудъявр. Таким образом, цель данной работы - оценить интенсивность загрязнения оз. Б. Вудъявр молибденом по результатам исследований его вертикального распределения и установления форм нахождения в толще современных ДО.

\section{Объект и методы исследования}

Колонки ДО мощностью 23 и 27 см были отобраны 26 апреля 2018 года в центральной части озера на глубине 37.4 м (рис. 1). Отбор проб производился при помощи пробоотборника открытого гравитационного типа со льда озера. После отбора ненарушенные колонки донных отложений транспортировались в лабораторию, где они были поделены на слои по 1 см для определения валового содержания микроэлементов и на слои по 5 см $(0-5,5-10,10-15$ и 18-23) для оценки форм нахождения тяжелых металлов. Измерение $\mathrm{pH}$ проводилось в лаборатории сразу после отбора образцов при помощи портативного $\mathrm{pH}-м е т р а-м и л л и в о л ь т м е т р а ~ \mathrm{H-420.} \mathrm{Для} \mathrm{определения} \mathrm{различных}$ форм нахождения тяжелых металлов использовалась методика (схема) последовательного экстрагирования форм элементов в почвах (Tessier et al., 1979), включающая в себя определение:

- водорастворимых форм (реагент $\left.\mathrm{H}_{2} \mathrm{O}\right)$;

- подвижных (обменных) форм (реагент $\mathrm{NH}_{4} \mathrm{CH}_{3} \mathrm{COO}$ );

- форм, связанных с гидроксидами железа и марганца (реагенты $0.04 \mathrm{M} \mathrm{NH}_{2} \mathrm{OH}^{*} \mathrm{HCl}$ в $\left.25 \% \mathrm{CH}_{3} \mathrm{COOH}\right)$ 
- форм, связанных с органическим веществом (реагенты $0.02 \mathrm{M} \mathrm{HNO}_{3}+30 \% \mathrm{H}_{2} \mathrm{O}_{2}$ и $3.2 \mathrm{M} \mathrm{NH}_{4} \mathrm{CH}_{4} \mathrm{COO}$ в $\left.20 \% \mathrm{HNO}_{3}\right)$;

- кислоторастворимые (остаточных) форм (реагент $\mathrm{HNO}_{3}$ ).

- минеральных (силикатных) форм, получаемых в результате вычета суммы концентраций всех вышеперечисленных форм из валовых концентраций.

Разложение образцов отложений для определения валовых концентраций элементов проводили путем кислотного вскрытия с использованием $\mathrm{HF}, \mathrm{HNO}_{3}$ и $\mathrm{HCl}$ в открытой системе. Содержание микроэлементов в пробах ДО определяли масс-спектральным методом на приборе XSeries-2 ICP-MS (Thermo Ficher Scientific) в аналитическом центре Института геологии КарНЦ РАН, г. Петрозаводск. Для статистической обработки данных и подготовки иллюстраций были использованы программы Statictica (version 10), Microsoft Office Excel 2016, ArcGIS for Desktop 10.4.1.

\section{Результаты и обсуждение}

ДО оз. Б. Вудъявр представляют из себя ил, в составе которого преобладают частицы размером от 0.001 до 0.25 мм (Югай, Даувальтер, 2011). Анализ вертикального распределения химических элементов в колонке ДО мощностью 27 см установил значительное увеличение концентраций многих элементов в верхних слоях озерных осадков по сравнению с нижележащими слоями. Это полностью согласуется с ранее проводимыми исследованиями (Денисов и др., 2006; Югай и др., 2013). Все элементы, ведущие себя описанным образом, попадают в ассоциацию №1 на факторной модели геохимических особенностей, изучаемых ДО (рис. 2). Кроме анализируемых ранее в ДО оз. Б. Вудъявр $\mathrm{Ni}, \mathrm{Cu}, \mathrm{Sr}, \mathrm{Zn}, \mathrm{Co}, \mathrm{Cd}, \mathrm{Pb}$ и $\mathrm{Mn}$ в этой группе оказались также $\mathrm{U}, \mathrm{V}, \mathrm{Sn}, \mathrm{Cs}$, группа редкоземельных элементов и другие. Эти элементы тесно коррелируют с фактором 1 , который имеет вес $58 \%$ от суммы всех факторов. Со вторым по значимости фактором, имеющим вес $23 \%$ от суммы всех факторов, тесно связны концентрации Мо и Аs. Следует отметить, что вертикальное распределение Мо имеет специфический вид с двумя пиками концентраций в верхней и нижней части изучаемой колонки ДО оз. Б. Вудъявр (рис. 3). При этом максимальное содержание этого металла (15 мг/кг) отмечается в нижней части колонки.

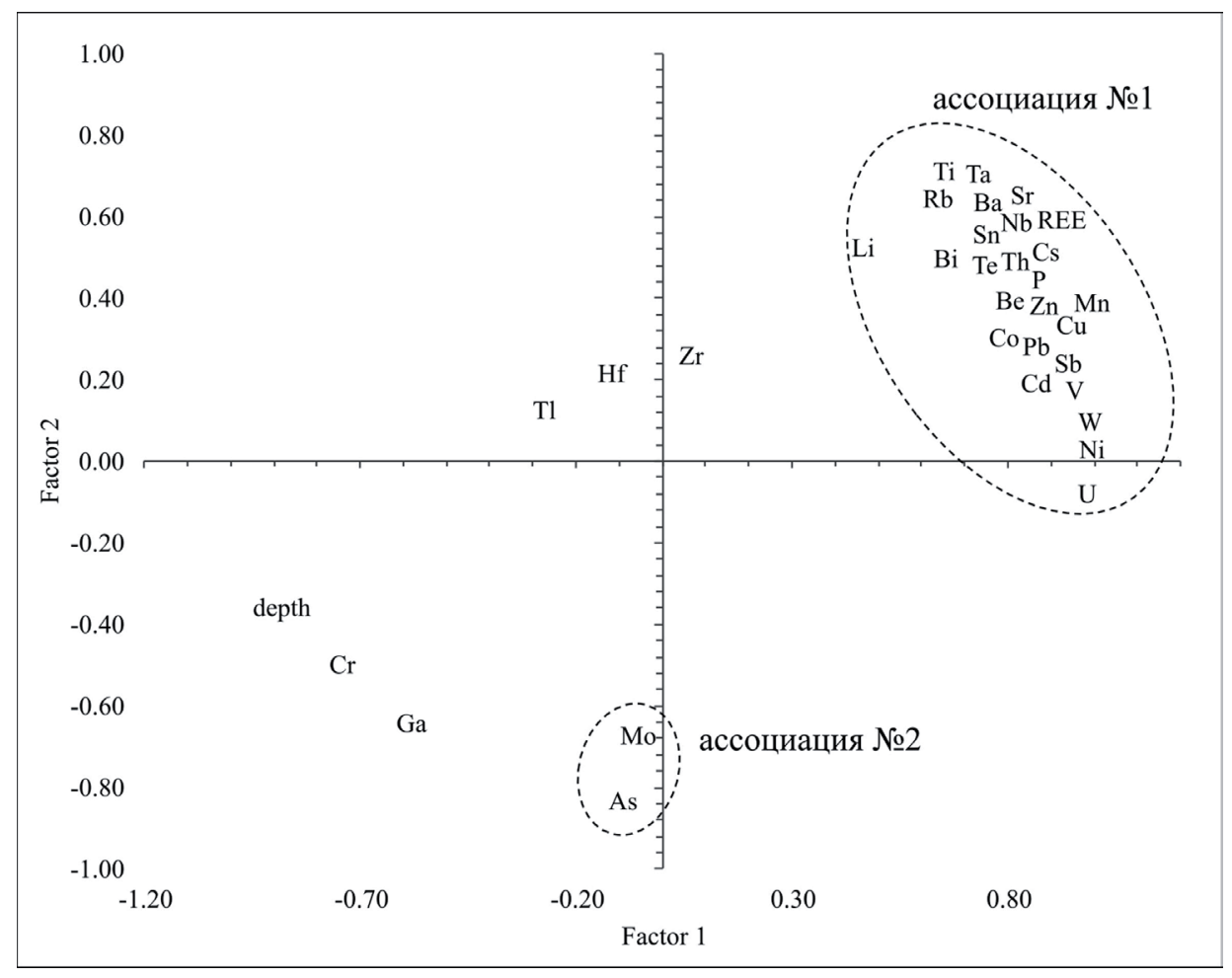

Рис. 2. Факторная модель геохимических особенностей донных отложений оз. Б. Вудъявр.

Fig. 2. Principal components analysis of elements from bottom sediments of Lake Bolshoi Vudjavr. 
Главными минералами Мо в рудах Хибинского массива являются молибденит $\mathrm{MoS}_{2}$, молибдит $\mathrm{MoO}_{3}$, вульфенит $\mathrm{PbMoO}_{4}$ и ферримолибдит $\mathrm{Fe}_{2}\left(\mathrm{MoO}_{4}\right)_{2}$ *8 $\mathrm{H}_{2} \mathrm{O}$. В результате выщелачивания из первичных минералов, в подземные и поверхностные воды, а затем и в ДО попадают значительные концентрации Мо, формируя специфические аномалии. Учитывая, что типичный минерал мышьяка (As) арсенопирит имеет преимущественно гидротермальное происхождение, как и молибденит, то возможен парагенизис этих минералов и как следствие совместная миграция их в водную среду и ДО озер. Этим можно объяснить их вхождение в ассоциацию № 2 факторной модели на рисунке 2. Кроме того, следует отметить, что на миграцию Мо в природных водах и дальнейшее осаждение влияет $\mathrm{pH}$ среды. В частности, в более щелочных условиях происходит растворение основных соединений Мо в водах, поступающих в оз. Б. Вудъявр (Чукаева, Матвеева, 2018). Отмечается, что между слоями изучаемой колонки ДО 19-20 и 20-21 см происходит резкое изменение $\mathrm{pH}$ ДО, чем, вероятно, и можно объяснить повышение концентраций Мо в нижней части колонки (рис. 3).

Анализ форм нахождения Мо в современных ДО оз. Б. Вудъявр показал, что преимущественно этот металл находится в нерастворимой минеральной форме, особенно в нижней части колонки ДО (рис. 4). Однако от 16 до 30 \% концентраций Мо в ДО оз. Б. Вудъявр аккумулировано органическими соединениями, доля которых в изученных осадках увеличивается в верхних слоях, что можно судить по увеличению концентраций фосфора. Именно в слое 0-5 см отмечается наибольшая значимость органики в накоплении Мо (рис. 4). В этом же слое ДО выявлена повышенная концентрация Мо в водорастворимой форме, что, вероятно, связано с непосредственным контактом с водной средой самых верхних слоев ДО оз. Б. Вудъявр. В более глубоких слоях значимость водорастворимой формы Мо снижается с 16 до 6-9\% от суммы всех форм нахождения этого металла. При этом роль подвижных форм Мо и форм, связанных с соединениями железа и марганца, незначительна во всей изученной толще осадков.

Таким образом, проведенные исследования позволили установить специфичность накопления Мо, поступающего в оз. Б. Вудъявр в результате деятельности рудников ОАО «Апатит», в колонке современных ДО. Наибольшее накопление этого металла приходится на нижнюю часть изученного разреза, где, кроме Мо повышенным накоплением характеризуется другой токсичный элемент As. Основной формой содержания Мо в изученных озерных ДО является минеральная форма, 


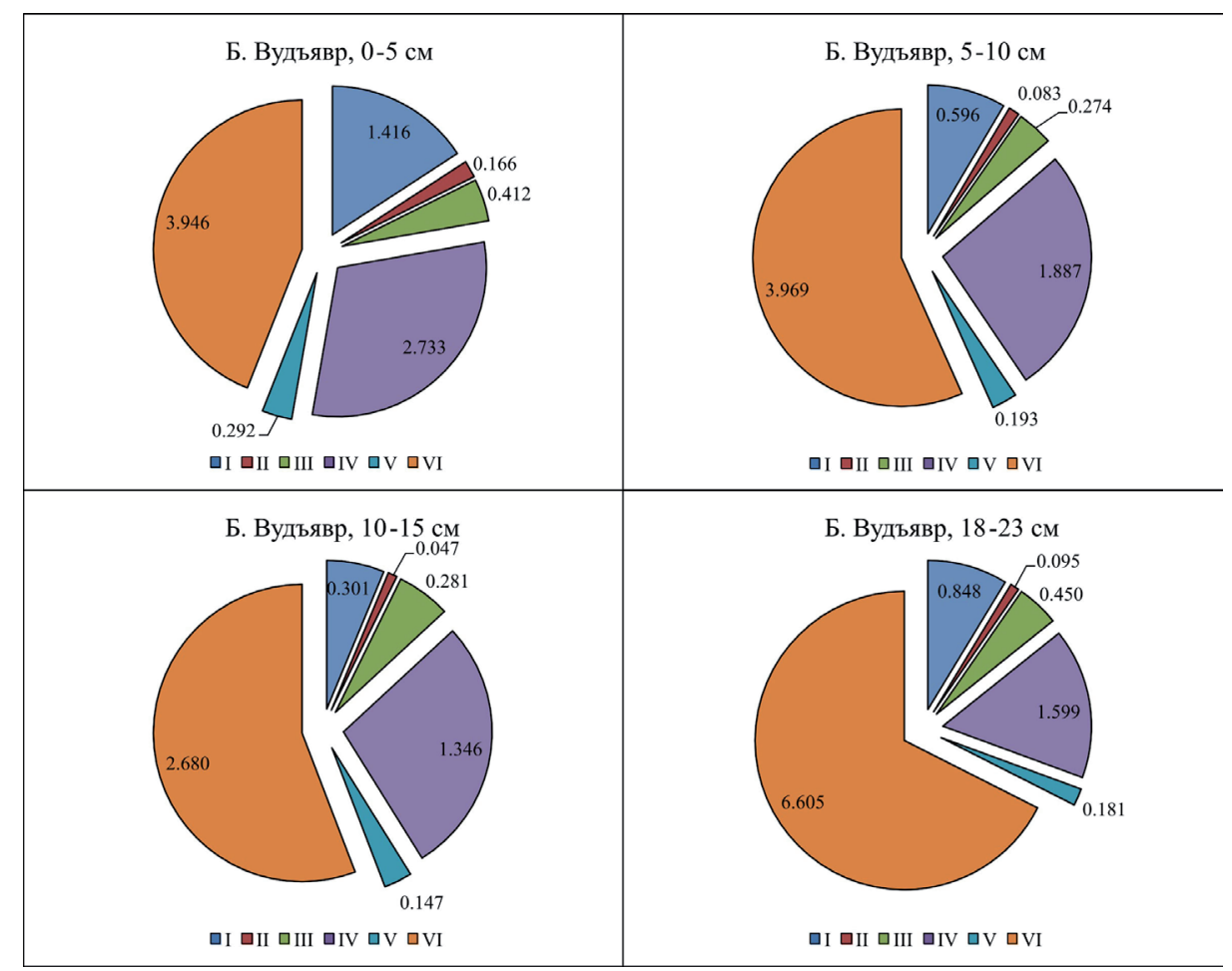

Рис. 4. Распределение разных форм нахождения Мо в ДО оз. Б. Вудъявр в слоях 0-5, 5-10, 10-15 и 18-23 см. Расшифровка: I - водорастворимые формы, II - обменные катионы (подвижные формы), III - формы, связанные с гидроокислами Fe и Mn, IV - формы, связанные с органическим веществом, V - кислоторастворимые (остаточные) формы, VI - минеральные формы.

Fig. 4. Forms of molybdenum in sediments of Lake Bolshoi Vudjavr (layers 0-5, 5-10, 10-15 and 18-23 cm). I - water associated fraction, II - exchangeable fraction, III - Fe-Mn oxide bound fraction, IV - organic bound fraction, $\mathrm{V}$ - residual fraction, VI - mineral phase.

однако органическим веществом аккумулируется от 16 до 30 \% поступающего в озеро Мо. В самом верхнем слое ДО высока роль водорастворимой формы этого металла, что связано с непосредственным контактом с водной средой.

Исследование выполнено при финансовой поддержке РФФИ в рамках научных проектов № 18-05-00897 и 18-05-60125, в рамках реализации гранта Президента Российской Федерации № МК-462.2019.5, а также в рамках темы НИР №0226-2019-0045.

\section{Литература}

1. Денисов Д.Б., Даувальтер В.А., Кашулин Н.А., Каган Л.Я. Долговременные изменения состояния субарктических водоемов в условиях антропогенной нагрузки (по данным диатомового анализа) // Биология внутренних вод. 2006. № 1. С. 24-30.

2. Сулименко Л.П., Кошкина Л.Б., Мингалева Т.А., Светлов А.В., Некипелов Д.А., Макаров Д.В., Маслобоев В.А. Молибден в зоне гипергенеза Хибинского горного массива. Мурманск. Изд-во: МГТУ. 2016.147 с.

3. Чукарева М.А., Матвеева В.А. Современное гидрохимическое состояние гидроэкосистем, находящихся под техногенным влияние АО «Апатит» // Водные ресурсы. 2018. Т. 45. № 6. С. 685-690.

4. Югай В.С., Даувальтер В.А., Кашулин Н.А. Содержание биодоступных форм соединений металлов в донных отложениях водоемов и коэффициент накопления $\left(\mathrm{K}_{\mathrm{d}}\right)$ как показатели экологической обстановки водоемов (на примере озер Мурманской области) // Вестник МГТУ. 2013. Т. 16. № 3. С. 591-600.

5. Югай В.С., Даувальтер В.А. Особенности донных отложений озер Малый и Большой Вудъявр // Квартер во всем его многообразии. Фундаментальные проблемы, итоги изучения и основные направления дальнейших исследований: Материлы VII Всероссийского совещания по изучению четвертичного периода (г. Апатиты, 12-17 сентября 2011 г.). Апатиты. СПб. 2011. Т. 2 (Л-Я). С. 333-336.

6. Tessier A., Campbell P.G., Bisson M. Sequential extraction proce-dure for the speciation of particulate trace metals // Analytical Chemistry. 1979. V. 51(7). P. 844-851. 